УДК 54-165.2+624.139

\title{
СИТАЛЛЫ ИЗ МЕСТНОГО СЫРЬЯ ДЛЯ ПРОИЗВОДСТВЕННЫХ ИННОВАЦИОННЫХ ИНФРАСТРУКТУР С ВЫСОКОЙ ТЕХНИКО-ЭКОНОМИЧЕСКОЙ ЭФФЕКТИВНОСТЬЮ В ЭКСТРЕМАЛЬНЫХ УСЛОВИЯХ КРАЙНЕГО СЕВЕРА
}

\author{
Мананков Анатолий Васильевич1,2, \\ mav.39@mail.ru \\ Гасанова Эльгюл Разим кызы', \\ elgyul91@mail.ru \\ 1 Томский государственный архитектурно-строительный университет, \\ Россия, 634003, г. Томск, пл. Соляная, 2. \\ 2 Национальный исследовательский Томский государственный университет, \\ Россия, 634050, г. Томск, пр. Ленина, 36.
}

\begin{abstract}
Актуальность исследования обусловлена проблемами эффективности освоения полезных ископаемых Заполярья за счет отказа от ввозимых за тысячи километров строительных материалов (бетонных изделий, кирпича и т. п.). Максимальная удаленность от промышленно-урбанизированных центров в сочетании с крайне суровыми природно-климатическими условиями Крайнего Севера значительно влияют на экономику добычи и экологию территории, где стоимость строительных материалов доходит до 70 \% себестоимости нефти и газа. Выход на шельфы арктических морей России и других стран требует инновационных материалов и прорывных технологий, включая строительство искусственных островов и подводных сооружений на шельфе. Для реализации таких прорывных технологий необходимы материалы и конструкции, обладающие многократно большей прочностью и долговечностью.

Цель исследования: разработать на основе сырья Полярного Урала многофункциональные материалы класса «сикам» с уникальным сочетанием физико-механических и химических свойств для передовых технологий.

Объекты исследований: отвальные горные породы базитового ряда золоторудных месторождений Полярного Урала, метасиликатные расплавы, стекла и ситаллы.

Методы исследований: теоретические и экспериментальные исследования исходных сырьевых материалов, расчет состава шихты для метасиликатных ситаллов - нового класса "сикам» (CKC), методы определения основных технологических параметров, изучения основных свойств продукции, методы создания новых инновационных строительных конструкций, методы обоснования технико- экономических показателей. Химический состав исходного сырья определен масс-спектральным методом с индуктивно связанной плазмой.

Результаты исследований. Обоснованы исходные составы и установлены физико-химические свойства петроситаллов класса "сикам» из местного сырья золоторудных месторождений Полярного Урала. Показана экономическая эффективность и экологическая целесообразность производства материала на месте с использованием дешевого энергоносителя (попутного газа) в сравнении с ввозимым железобетоном. В особых условиях Арктики этот материал незаменим для производства свайно-эстакадной дорожной конструкции и строительства на ее основе долговечной транспортной инфраструктуры, промышленных и гражданских объектов в условиях вечной мерзлоты и арктического шельфа.
\end{abstract}

\section{Ключевые слова:}

Горные породы Полярного Урала, петроситаллы, изоморфизм, мономинеральность, метасиликаты, субсолидусная несмесимость, спинодальный распад, сикам, кристаллохимический подход,

свайно-эстакадная дорожная конструкция, транспортная, промысловая, гражданская инфраструктура.

\section{Введение}

Крайне суровые природно-климатические условия Заполярья (рис. 1) и расширение масштабов освоения его недр с выходом на шельфы арктических морей, где невозможно использование традиционных морских буровых платформ, требуют разработки и применения высокопрочных и высокоэффективных строительных конструкций самого широкого спектра для промышленного, транспортного и гражданского строительства. Неотложная потребность в таких конструкциях и их дорогостоящая доставка с «материка», в свою очередь, сформировали идею значительного снижения себестоимости путем организации их производства на месте использования, из местного сырья и дешевых местных энергоносителей.
Для создания научной базы заполярного материаловедения и строительной отрасли на собственных сырьевых ресурсах Администрация ЯНАО в 2011 г. обратилась к проф. А.В. Мананкову с предложением: исследовать ресурсные возможности, найти местное минеральное сырье и разработать составы и способы получения ситаллы класса «сикам» (CKC).

\section{Историческая справка}

Ситаллы - новые конструкционные материалы, появились лишь в средине ХХ в. при развитии ракетной техники. С тех пор ситаллы становятся инновационными материалами в самых различных сферах. Существует несколько классификаций ситаллов: по составу исходного сырья (петро- 


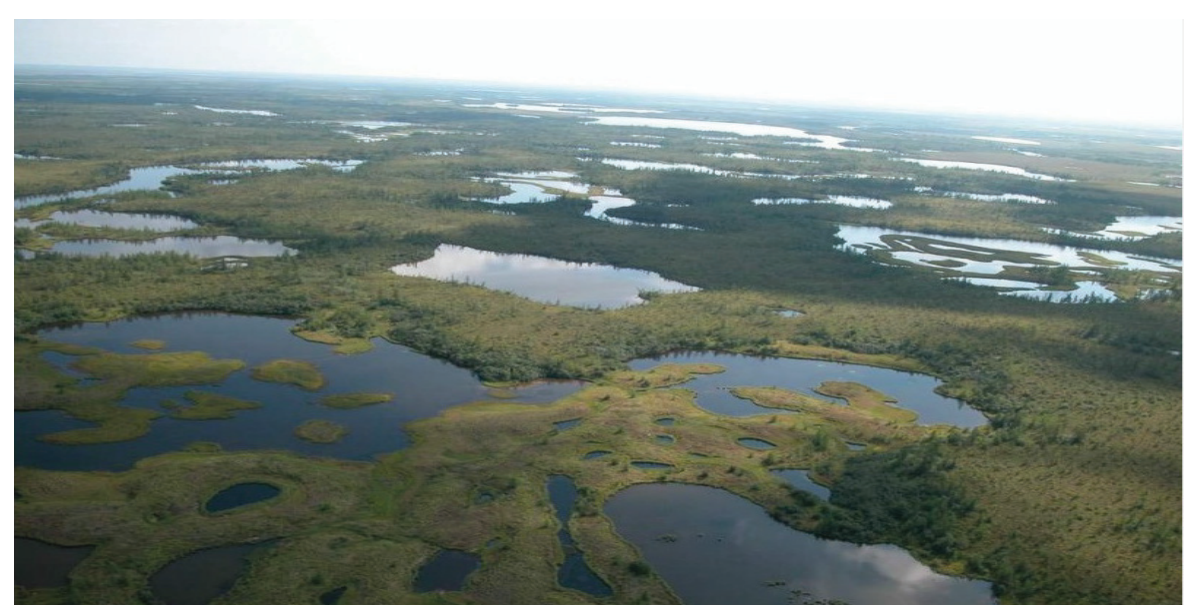

Рис. 1. Дорожные условия: тундра Ямала летом

Fig. 1. Road conditions: the tundra of Yamal in summer

ситаллы, шлакоситаллы, технические ситаллы), по минеральному составу ситаллов (пироксеновые или сикамы, сподуменовые, кордиеритовые, высококремнеземистые, свинецсодержащие и т. п.), по свойствам ситаллов (износостойкие, кислотостойкие, жаропрочные, а также специальные поглощающие тепловые нейтроны и т. п.) [1-5].

В Томской научной школе физической геохимии и минералогии профессора А.В. Мананкова, основанной по инициативе профессора И.К. Баженова, с 1972 г. проводятся фундаментальные и экспериментальные исследования многокомпонентных силикатных систем, разработана петрогеохимическая классификация природного сырья (49 месторождений) и промышленных отходов (26 предприятий) с выделением восьми петрогеохимических классов, что привело к открытию нового 19 класса многофункциональных стеклокристаллических материалов (класса СИКАМ) и технологий их производства $[6,7]$. На открытие этого класса материалов имеется Свидетельство на товарный знак № 92355 [8], а также получено около 40 патентов и авторских свидетельств на изобретения. Появление этих материалов уже оказалось востребованным многими отраслями и новой техникой. Важно подчеркнуть, что стала возможной разработка новых малозатратных и высокоэффективных технологий производства новых конструкций, обладающих особенно высокой прочностью и надежностью в экстремальных условиях не только на Земле, но и в космосе [9].

Этот класс представлен тремя подклассами: 1) плотные массивные петро-шлакосикамы метасиликатного состава; 2) вспененные (тепло-звукоизоляционные) пеносикамы и 3) синтетический трансволластонит (массивные изделия любого цвета, текстуры как облицовочный материал и диспергированный до наноразмерных волокон в качестве модифицирующего наполнителя, все более востребованного в современном материаловедении от разметки на дороге до космоса) [2, 7].
Важным свойством массивных СКС является их соответствие твердому раствору со структурой диопсида для условий неравновесной кристаллизации, когда в состав диопсида при $\mathrm{P}=1$ атм. может входить до 40 мол. \% $\mathrm{CaAl}_{2} \mathrm{SiO}_{6}$, до 50 мол. \% $\mathrm{CaFe}_{2} \mathrm{SiO}_{6}$ и до 30 мол. \% $\mathrm{CaAl}_{2} \mathrm{TiO}_{6}$ [10]. Широкий изоморфизм при направленной кристаллизации метасиликатных твердых растворов придает возможность получения наиболее прочных материалов с уникальным сочетанием химической, термической стойкости и высокой сопротивляемости механическому истиранию.

Исходное сырье для СКС может быть различным: 1) магматические горные породы преимущественно с дефицитом в составе кремнезема (ультраосновные, основные интрузивные и эффузивные породы); 2) метаморфические и осадочно-метаморфические горные породы; 3) разнообразные силикатсодержащие промышленные отходы добычи, обогащения и переработки практически любых полезных ископаемых (рудных, нерудных, энергетических каменных углей и т. п.) после извлечения из них дефицитных металлов - от черных и цветных до редких элементов, лантаноидов и актиноидов. По нашим подсчетам в первом приближении, такая стратегия использования минеральных ресурсов позволит сократить на 25 \% добычу первичных полезных ископаемых [11].

Для производства вспененного материала - пеносикама, высокоэффективного теплоизоляционного стенового материала, в качестве исходного сырья нами, в первую очередь, исследованы покровные легкоплавкие суглинки (более 30 месторождений), распространенные по долине реки Обь и ее многочисленных притоков от Алтая до Колтогорского месторождения на севере Томской области, т. е. по всей Западно-Сибирской низменности. Новизна подтверждается рядом Российских патентов и Международным патентом на составы и технологии [12]. Новые материалы и конструкции прошли успешные опытно-заводские испытания. 
Управление свойствами обеспечивается реализацией разработанного авторами способа расчета исходного химического состава шихты с помощью модуля кислотности-основности, а также автоматизированной технологии управляемого синтеза фрактальной микросферолитовой структуры петроситалла СКС в поле субсолидусной несмесимости. Автоматизация управляемого синтеза петроситалла заключается в разработке кристаллохимической формулы для расчета состава шихты на мономинеральный метасиликатный состав с позиции выявленных пределов изоморфизма $[6,10]$.

Объектами исследования являются полиморфные модификации цепочечных метасиликатов моноклинной сингонии, формирующихся в неравновесных условиях, моделируемых аттрактором кристаллизации с точками бифуркации.

Предметом исследования, как более детализированной характеристикой объекта, послужили фазовые превращения на стадиях зародышеобразования и роста кристаллов в метасиликатной системе «стекло-кристалл», для выявления особенностей процессов, оптимизации технологических параметров и их влияния на свойства СКС.

\section{Исходные породы и расчет состава шихт для СКС}

Широко известно, что наличие местного природного сырья существенно удешевляет производственные затраты на строительные материалы, так как сырье в удельном весе стоимости готовой продукции стеклокристаллических материалов занимает не менее 48 \% [3, 7, 13-15]. Далее привозные с материка строительные материалы в сметах строящихся предприятий в условиях Крайнего Севера составляют доминирующую долю всех затрат. Стоимость материалов для дорог III категории составляет 45 млн р/1 км $[6,9,10]$.

Авторы статьи опробовали промышленные отходы ряда золоторудных месторождений Полярного Урала. Были выбраны отвальные породы базальт-андезитового ряда (табл. 1), для которых выполнены минералого-петрографические, геохимические и экспериментальные исследования этих горных пород с целью получения из них петроситаллов класса СКС.

Результаты химических анализов - традиционно основа для теоретического конструирования сырьевых композиций ситаллов. Для контроля состава шихты предлагается «модуль кислотностиосновности $\mathrm{M}_{\mathrm{K}}$ " [16-18]. В настоящее время известен целый ряд новых моделей структуры стекла различного состава и их кристаллизации [19-25]. Разработанный способ расчета состава шихты создан на основе открытых нами механизмов фазовых превращений в субсолидусной области на наноразмерных уровнях структуры стекла и установленных экспериментально пределов изоморфизма при направленной кристаллизации. Модуль кислотности-основности $M_{k}$ позволяет количественно учитывать поведение амфотерных оксидов $\mathrm{Al}^{3+}$ и $\mathrm{Fe}^{3+}$ и др., которые могут принимать участие не только в октаэдрической, но и тетраэдрической подрешётке моноклинных метасиликатов:

$$
M_{k}=\frac{\left[\begin{array}{l}
\mathrm{SiO}_{2}+\mathrm{TiO}_{2}+ \\
+\left\{\begin{array}{l}
\left(\mathrm{Al}_{2} \mathrm{O}_{3}+\mathrm{Fe}_{2} \mathrm{O}_{3}\right)- \\
-\left[\begin{array}{l}
(\mathrm{Na}, \mathrm{K}) \mathrm{O}+ \\
+0,5(\mathrm{CaO}-\mathrm{MgO}-\mathrm{FeO})
\end{array}\right]
\end{array}\right]
\end{array}\right.}{\left[\begin{array}{l}
\mathrm{K}_{2} \mathrm{O}+\mathrm{Na}_{2}+\mathrm{CaO}+\mathrm{MgO}+ \\
+\mathrm{FeO}+\Delta\left(\mathrm{Al}_{2} \mathrm{O}_{3}+\mathrm{Fe}_{2} \mathrm{O}_{3}\right)
\end{array}\right]},
$$

где $\Delta\left(\mathrm{Al}_{2} \mathrm{O}_{3}+\mathrm{Fe}_{2} \mathrm{O}_{3}\right)$ - количество амфотерных оксидов в октаэдрической подрешетке $M_{2}$, равное сумме молекулярных количеств $(\mathrm{Na}, \mathrm{K})_{2} \mathrm{O}+0,5[\mathrm{CaO}-(\mathrm{MgO}+\mathrm{FeO})]$.

В основе способа заложен принцип изоструктурности и кристаллохимического единства цепочечных метасиликатов в условиях управляемой кристаллизации. Этот принцип реализуется при любых вариациях исходного состава шихты, если выполняется условие: $M_{k}=1$. С помощью значения $M_{k}$ можно учитывать количественно соотношение минальных фаз, слагающих изоморфные серии, что открывает перспективу создания надежного метода предсказания свойств и качества ситаллов в метасиликатных системах.

Таблица 1. Химические составы отвальных пород золоторудных месторождений

Table 1. Chemical compositions of gold ore deposit dumps

\begin{tabular}{|c|c|c|c|c|}
\hline $\begin{array}{c}\text { Оксиды } \\
\text { Oxides }\end{array}$ & $\begin{array}{c}\text { Базальт } \\
\text { Basalt (1) }\end{array}$ & $\begin{array}{c}\text { Основной } \\
\text { пикроба- } \\
\text { зальт } \\
\text { Main picro- } \\
\text { basalt (2) }\end{array}$ & $\begin{array}{c}\text { Низкоще- } \\
\text { лочной } \\
\text { андезит } \\
\text { Low alkaline } \\
\text { andesite (3) }\end{array}$ & $\begin{array}{c}\text { Высокоще- } \\
\text { лочной } \\
\text { андезит } \\
\text { High alkaline } \\
\text { andesite (4) }\end{array}$ \\
\hline $\mathrm{SiO}_{2}$ & 48,67 & 45,08 & 62,30 & 57,66 \\
\hline $\mathrm{TiO}_{2}$ & 0,37 & 0,59 & 1,05 & 0,79 \\
\hline $\mathrm{Al}_{2} \mathrm{O}_{3}$ & 16,93 & 14,85 & 11,98 & 15,14 \\
\hline $\mathrm{Fe}_{2} \mathrm{O}_{3}$ & 5,01 & 8,54 & 3,73 & 2,82 \\
\hline $\mathrm{FeO}_{\mathrm{ng}}$ & 6,34 & 7,69 & 5,51 & 4,27 \\
\hline $\mathrm{MgO}+\mathrm{MnO}$ & 5,80 & 7,73 & 3,05 & 3,36 \\
\hline $\mathrm{CaO}$ & 11,84 & 9,95 & 5,96 & 5,11 \\
\hline $\mathrm{Na}_{2} \mathrm{O}$ & 2,00 & 1,40 & 1,43 & 2,93 \\
\hline $\mathrm{K}_{2} \mathrm{O}$ & 0,12 & 0,17 & 2,33 & 2,20 \\
\hline $\mathrm{P}_{2} \mathrm{O}_{5}$ & 0,02 & 0,07 & 0,12 & 0,31 \\
\hline $\mathrm{H}_{2} \mathrm{O}$ & 0,28 & 0,30 & 0,17 & 0,38 \\
\hline П.п.п. & 2,31 & 2,74 & 1,26 & 4,21 \\
\hline Сумма/Sum & 99,69 & 99,11 & 98,89 & 99,18 \\
\hline
\end{tabular}

Экспериментальное изучение механизмов кристаллизации позволило установить прямые и обратные связи химического состава СКС с наноструктурой стекла и кинетикой ситаллизации, а также физико-химическими свойствами. Установлено, что по мере приближения исходной шихты к мономинеральному составу ускоряются процессы зародышеобразования и улучшаются физикохимические свойства материала [26].

Проверка качества исходных составов, конструируемых по формуле (1), осуществляется пересчетом по кислородному методу, т. е. на шесть 
таблица 2. Кристаллохимические формулы петроситаллов

Table 2. Crystallochemical formulas of petrositalls

\begin{tabular}{|c|c|c|c|}
\hline \multirow{2}{*}{$\begin{array}{c}\text { № пробы } \\
\text { Sample no. }\end{array}$} & \multicolumn{3}{|c|}{ Подрешетки в формуле пироксенов/Sublattices in the pyroxene formula } \\
\cline { 2 - 4 } & $M_{2}$ & $M_{1}$ & $R$ \\
\hline 1 & $\left(\mathrm{Ca}_{0,86} \mathrm{Na}_{0,13} \mathrm{~K}_{0,01}\right)$ & $\left(\mathrm{Ca}_{0,06} \mathrm{Mg}_{0,29} \mathrm{Fe}_{0,18}^{+2} \mathrm{Fe}_{0,13}^{+3} \mathrm{Al}_{0,34}\right)$ & $\left(\mathrm{Si}_{1,65} \mathrm{Ti}_{0,01} \mathrm{Al}_{0,34}\right) \mathrm{O}_{6}$ \\
\hline 2 & $\left(\mathrm{Ca}_{0,9} \mathrm{Na}_{0,09} \mathrm{~K}_{0,01}\right)$ & $\left.\mathrm{Mg}_{0,4} \mathrm{Fe}_{0,22}^{+2} \mathrm{Fe}_{0,22}^{+3} \mathrm{Al}_{0,20}\right)$ & $\left(\mathrm{Si}_{1,57} \mathrm{Ti}_{0,02} \mathrm{Al}_{0,41}\right) \mathrm{O}_{6}$ \\
\hline 3 & $\left(\mathrm{Ca}_{0,83} \mathrm{Na}_{0,08} \mathrm{~K}_{0,09}\right)$ & $\left(\mathrm{Ca}_{0,4} \mathrm{Mg}_{0,13} \mathrm{Fe}_{0,13}^{+2} \mathrm{Fe}_{0,08}^{+3} \mathrm{Al}_{0,25}\right)$ & $\left(\mathrm{Si}_{1,81} \mathrm{Ti}_{0,02} \mathrm{Al}_{0,16}\right) \mathrm{O}_{6}$ \\
\hline 4 & $\left(\mathrm{Ca}_{0,74} \mathrm{Na}_{0,18} \mathrm{~K}_{0,09}\right)$ & $\left(\mathrm{Ca}_{0,29} \mathrm{Mg}_{0,16} \mathrm{Fe}_{0,11}^{+2} \mathrm{Fe}_{0,07}^{+3} \mathrm{Al}_{0,38}\right)$ & $\left(\mathrm{Si}_{1,79} \mathrm{Ti}_{0,02} \mathrm{Al}_{0,18} \mathrm{P}_{0,01}\right) \mathrm{O}_{6}$ \\
\hline
\end{tabular}

Примечане. Номера проб соответствуют номерам в табл. 1.

Note. Sample numbers correspond to the numbers in the table 1.

атомов кислорода с учетом пределов изоморфных замещений в трех подрешетках моноклинных пироксенов $M_{2}, M_{1}$ и $R$ (табл. 2).

Полученные мономинеральные метасиликаты с обширным полем изоморфных замещений являются наиболее перспективными, поскольку в структуре стекла возникают когерентные наноструктуры [27, 28], которые энергетически связаны друг с другом гармоничными отношениями.

\section{Экспериментальные исследования условий} плавления шихт и ситаллизации гомогенных стекол

Подготовленные исходные шихты расплавлялись до гомогенности в алундовых тиглях в силитовой печи при $1360-1400^{\circ} \mathrm{C}$ и времени плавления $1,5-2,0$ ч.

Для определения температур зародышеобразования и роста кристаллов, стекла (после закаливания и отжига) исследованы с помощью дифференциально-термического метода (ДТА) на приборе NETZSCHSTA 409 PC/PG в интервале $20-1100{ }^{\circ} \mathrm{C}$ в лаборатории ЦКП аналитического центра ТГУ (табл. 3).

Таблица 3. Результаты ДТА стекол на основе базитов Полярного Урала

Table 3. Results of glasses DTA based on the basilites of the Polar Urals

\begin{tabular}{|c|c|c|c|c|}
\hline $\begin{array}{c}\text { № пробы } \\
\text { Sample no. }\end{array}$ & $T_{1},{ }^{\circ} \mathrm{C}$ & $\begin{array}{c}E_{1, \mathrm{MBT} / \mathrm{Mr}} \\
(\mathrm{mW} / \mathrm{mg})\end{array}$ & $T_{2,}{ }^{\circ} \mathrm{C}$ & $\begin{array}{c}E_{2, \mathrm{MBT} / \mathrm{Mr}} \\
(\mathrm{mW} / \mathrm{mg})\end{array}$ \\
\hline 1 & 723 & 0,391 & 905 & 0,494 \\
\hline 2 & 711 & 0,423 & 897 & 0,812 \\
\hline 3 & 742 & 0,321 & 951 & 0,591 \\
\hline 4 & 727 & 0,360 & 964 & 0,686 \\
\hline
\end{tabular}

Примечание: $T_{1}$ - температуры зародышеобразования, $T_{2}$ температуры роста кристаллов, $E_{1}$ - энергия активации зародышеобразовании, Е2 - энергия роста кристаллов (Аналитик E.M. Асочакова). Номера 1-4 соответствуют номерам в табл. 2.

Note. $T_{1}$ is the nucleation temperatures; $T_{2}$ are the crystal growth temperatures; $E_{1}$ is the nucleation activation energy; $E_{2}$ is the crystal growth energy (Analyst $E$. Asochakova). Numbers 1-4 correspond to the numbers in the table 2.

Гомогенные стекла (на основе этих данных) подвергались кинетическим исследованиям по авторскому способу [29], позволяющему вычленить в технологическом процессе кристаллизации с помощью комплекса структурно чувствительных методов изотермическую и нестационарную компо- ненты фазовых превращений и таким образом получить надежные критерии для технологических параметров всего процесса. Анализ результатов, в частности, показал, что оптимальное время изотермического нагрева на ступенях $\mathrm{T}_{1}$ и $\mathrm{T}_{2}$ должно быть в пределах 45 мин.

Используя оптимальные составы шихт и температурно-временные технологические параметры, получены плоские плитки и фасонные изделия стандартных размеров для определения литейнотехнологических, механических и др. свойств. Образцы продукции не имеют свилей, признаков деформации. Макроскопически ситаллы обладают однородной текстурой и монотонным цветом в серовато-зеленых тонах. Из них изготовлены препараты для изучения состава СКС оптическими методами, рентгенофазовым анализом (РФА) и т. п.

\section{Минеральный состав, структуры, текстуры \\ и физико-химические свойства петроситаллов класса СКС}

Под микроскопом нано-микроструктура однородная, средний размер кристаллов 5-8 мкм (рис. 2).

По результатам РФА метасиликатные петроситаллы соответствуют твердому раствору состава «моноклинные пироксены - $\beta$-волластонит» либо чистому диопсиду (рис. 3), либо пироксенам диопсид-геденбергитового ряда (рис. 4), что и определяет, в конечном счете, некоторый разброс в целом достаточно высоких их эксплуатационных свойств (табл. 4).

Микротвердость (Н) определена помощью микроскопа ПМТ-3. Пределы колебания среднестатистических данных $H=750-920$ кг/ мм² $^{2}$ На стандартных образцах получены значения механической прочности при сжатии. $\sigma_{\text {сж}}=700-720$ МПА, что в $1,4-2,5$ раза выше, чем у каменного литья. Намечается тенденция роста этих свойств при изоморфном замещении $\mathrm{Fe}^{3+}$ на $\mathrm{Al}^{3+}$ при равном количестве щелочных катионов.

В управлении и особенно при совершенствовании технологических процессов, как отмечено выше, важную роль играют знания особенностей механизмов элементарных стадий процесса кристаллизации. Это обусловлено появлением новых методов и, как следствие, нового экспериментального материала, который не всегда согласуется с тради- 

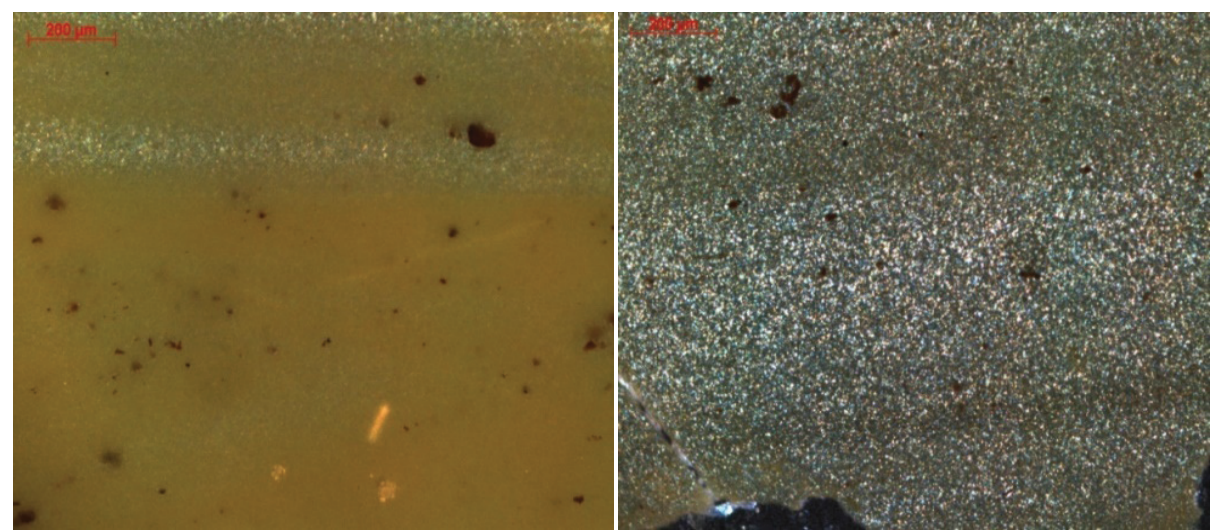

Рис. 2. Зависимость микроструктуры петроситалла от параметров $T_{1}$ и $T_{2}$. Слева - 15 мин, справа - 50 мин

Fig. 2. Influence of isothermal heating time at stages $T_{1}$ and $T_{2}$ on crystallization degree. Left -15 minutes, right -50 minutes

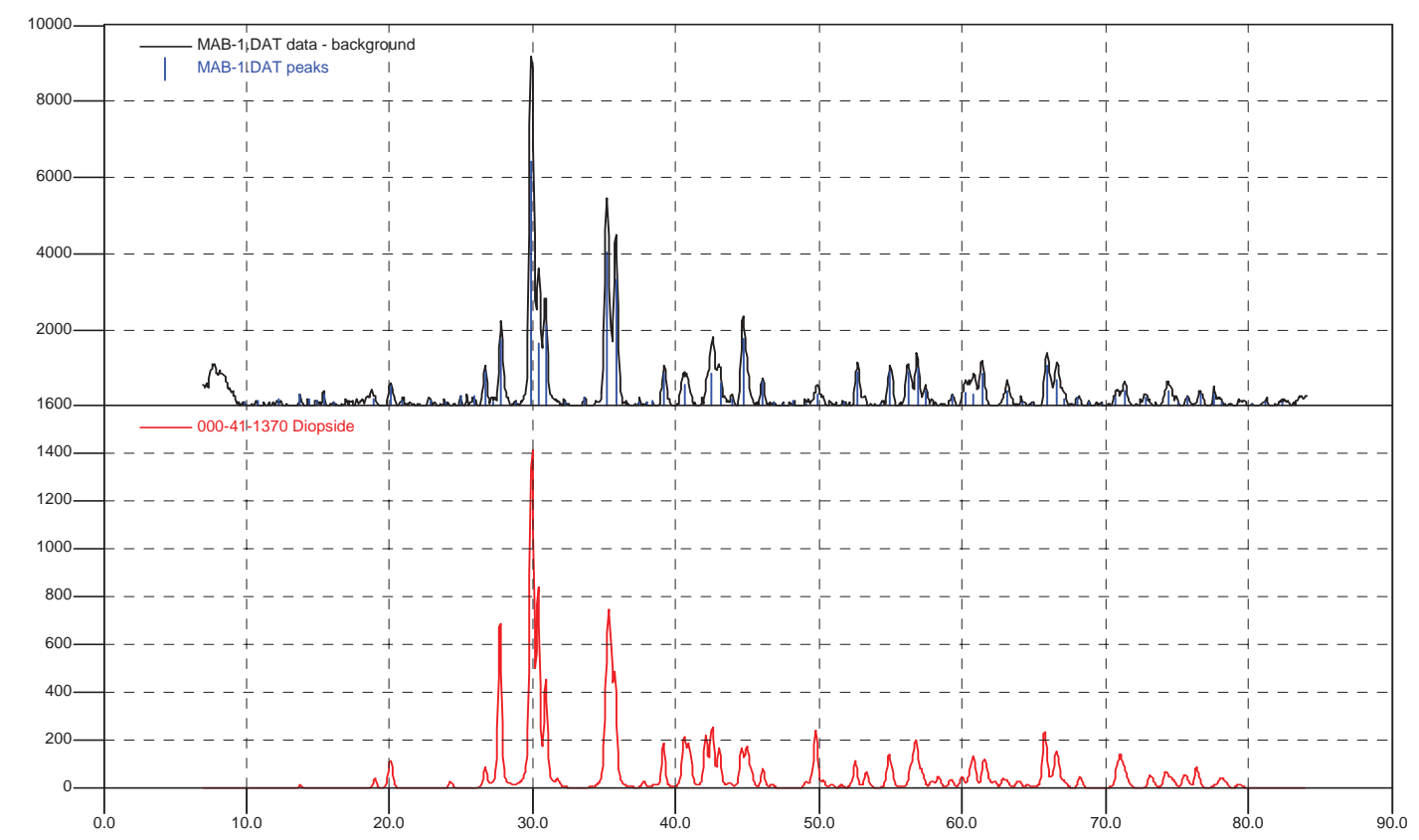

Рис. 3. Дифрактограмма петроситалла класса СКС, на основе базальта (№ 1) Полярного Урала (вверху) в сравнении с эталонным диопсидом № 000-41-1370 (внизу)

Fig. 3. X-ray picture of petrositall from sample № 1 (top) and Reference diopside no. 000-41-1370 (bottom)
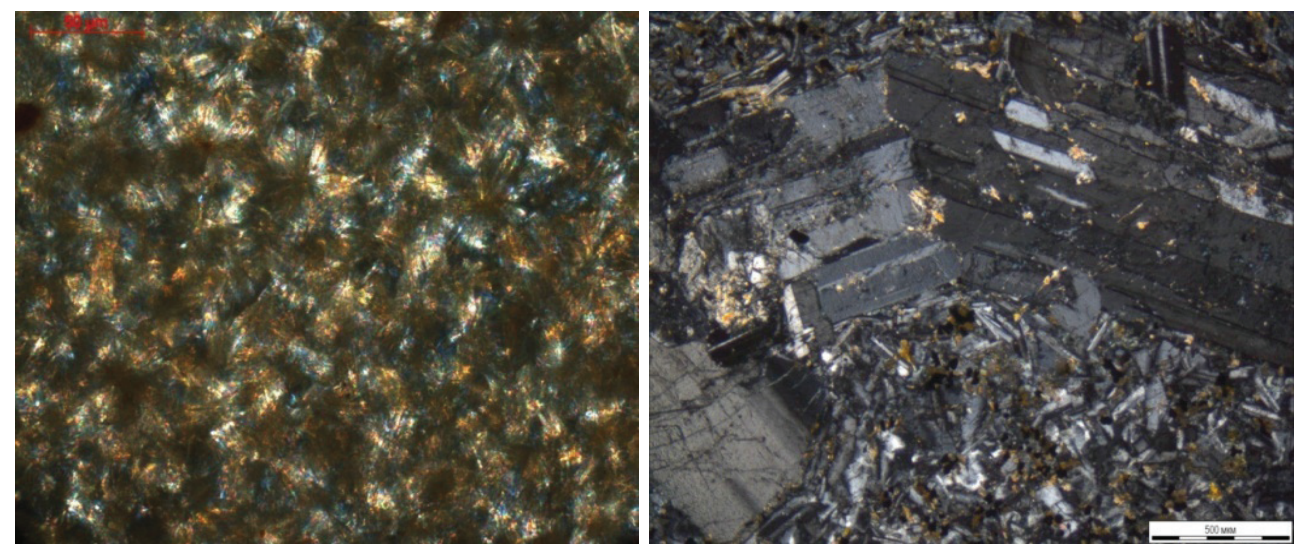

Рис. 4. Микросферолитовая структура петроситалла (слева) и микроструктура исходного пикробазальта (справа)

Fig. 4. Spherolitesubmicrostructure of the sitall, obtained at optimal technological parameters (left) in comparison with the original rock: porphyry structure with inclusions of plagioclase in the microallotriomorphic mass of gabbro-porphyrite (right) 
ционными представлениями, а иногда и вовсе не находит в них объяснения. Такая ситуация возникает при описании высоких скоростей диффузии и роста кристаллов СКС $[17,18]$.

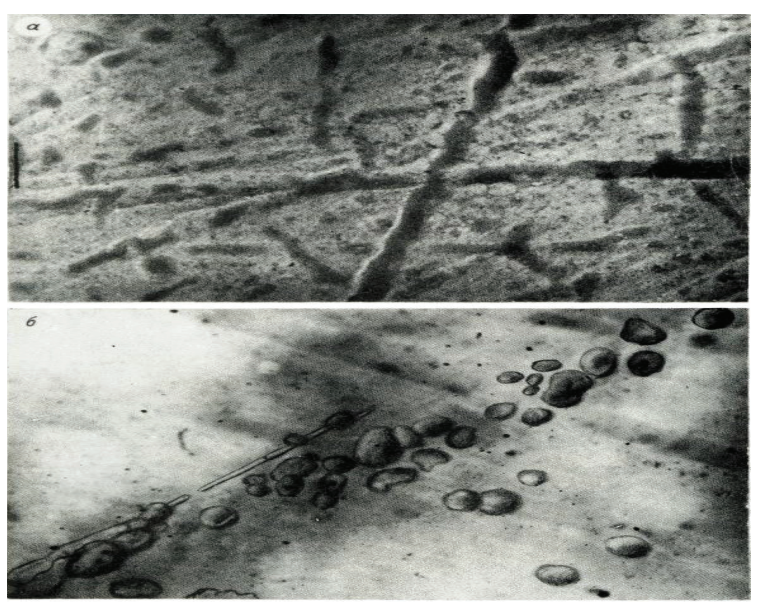

Рис. 5. Динамика формирования субмикроструктуры метастабильного распада на стадии гомогенного зародышеобразования в СКС. Вверху - 10 мин, внизу 30 мин. Увел. 10000

Fig. 5. Dynamics of submicrostructures of metastable decay formation at the stage of homogeneous nucleation in SCS. Top - 10 minutes, bottom - 50 minutes. Enlarge 10000

Результаты экспериментальных исследований фазовых превращений в системе «стекло-ситалл» позволили выявить механизм субсолидусной метастабильной наноразмерной ликвации на стадии зародышеобразования (рис. 5), а на стадии роста кристаллов наноразмерный гомогенный и субмикрогетерогенный нуклеационные механизмы. Комплексный эффект этих установленных на на- ноуровне механизмов фазовых превращений позволил объяснить не укладывающееся до сих пор в теории резкое ускорение процесса ситаллизации. Эти новые механизмы процессов фазовых превращений послужили основой для создания инновационных материалов и технологий, в которых время кристаллизации в системе стекло-кристалл даже по сравнению с передовыми зарубежными технологиями производства ситаллов (США, Японии) сокращается практически на два порядка.

Способ моделирования шихты и производства CKC с заданными и управляемыми свойствами получил научное и экспериментальное обоснование в лабораторных условиях, а масштабное подтверждение - по результатам заводских испытаний на Первоуральском заводе каменного литья и в ТГАСУ, где испытали плиты размером $4 \times 2 \times 0,25$ м и другие материалы.

Сикамы, созданные из минерального сырья Полярного Урала, по физико-химическим свойствам (прочность при изгибе и сжатии, сопротивление истиранию, химическая стойкость к серной кислоте, щелочам, температура начала размягчения и другие показатели) превосходят известные альтернативные материалы (табл. 4).

Из этой же таблицы следует, что применение сикамов значительно удешевляет строительство самых различных сооружений для бурно развивающихся отраслей экономики крайнего Севера. Это касается в первую очередь транспортной и промышленной инфраструктуры с применением петроситалловых дорожных плит, трубопроводов на винтовых сваях, взлетно-посадочных полос аэродромов и военных авиабаз, грузовых и нефтегазовых морских терминалов, портов и пирсов на арктическом побережье, искусственных островов и кустов бурения на болотах, озерах и мелководном

Таблица 4. Основные свойства синтезированных петроситаллов класса «сикам», каменного литья и других конструкционных материалов

Table 4. The main properties of synthesized petrositalls of the class "sikam», stone casting and other construction materials

\begin{tabular}{|c|c|c|c|c|}
\hline $\begin{array}{l}\text { Показатель (свойство) } \\
\text { Indicator (property) }\end{array}$ & $\begin{array}{l}\text { Петроситаллы класса «сикам» } \\
\text { Petrositalls, class «Sikam» }\end{array}$ & $\begin{array}{l}\text { Каменное литье* } \\
\text { Stone casting* }\end{array}$ & $\begin{array}{c}\text { Бетон* } \\
\text { Concrete* }\end{array}$ & $\begin{array}{c}\text { Чугун* } \\
\text { Castiron* }\end{array}$ \\
\hline $\begin{array}{l}\text { Коэффициент линейного расширения (KTP) } 10^{70} \mathrm{C}^{-1} \\
\text { Linear expansion coefficient (LEC) } 10^{\circ} \mathrm{C}^{-1}\end{array}$ & $65-114$ & $48-100$ & 100 & 100 \\
\hline $\begin{array}{l}\text { Температура начала размягчения, }{ }^{\circ} \mathrm{C} \\
\text { Softening temperature, }{ }^{\circ} \mathrm{C}\end{array}$ & $950-1100$ & $900-1050$ & - & - \\
\hline 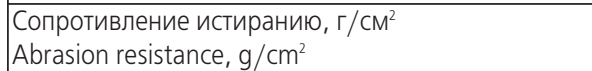 & $0,015-0,04$ & $0,02-0,08$ & - & - \\
\hline $\begin{array}{l}\text { Предел прочности, МПА: при статическом изгибе } \\
\text { Strength limit, MPA: with static bending }\end{array}$ & $100-188$ & $47-80$ & - & 280 \\
\hline $\begin{array}{l}\text { Предел прочности, МПА: при сжатии } \\
\text { Strength limit, MPA: at compression }\end{array}$ & 707-909 & $250-500$ & $5-60$ & $800-1000$ \\
\hline $\begin{array}{l}\text { Хим. стойкость } \\
\text { Chem. resistance, \%: } \mathrm{H}_{2} \mathrm{SO}_{4} \mathrm{NaOH}\end{array}$ & $94,6-99,998,0-99,0$ & $\begin{array}{l}99,8 \\
98,5\end{array}$ & - & - \\
\hline $\begin{array}{l}\text { Стоимость } 1 \mathrm{~m}^{3} \text { материалов (p.) } \\
\text { Cost of } 1 \mathrm{~m}^{3} \text { of materials (rubles) }\end{array}$ & $\begin{array}{c}9000 \\
\text { на заводе петроситаллов } \\
\text { в п. Харп, ЯНАO } \\
\text { at the Petrosital Plant } \\
\text { in the Kharp village, YaNAO }\end{array}$ & 30000 & $\begin{array}{c}18000-24000 \\
\text { B ЯHAO } \\
\text { in YaNAO }\end{array}$ & 112000 \\
\hline
\end{tabular}

Примечание:* - по данным [3].

Note:* according to the data [3]. 
шельфе с заморозкой основания промплощадок криосваями, а также подводных кессонных буровых станций (типа «подводный колокол»), смонтированных из ситалловых сферических фуллеровых тюбингов и т. п. [6, 9, 10].

Метасиликатные ситаллы класса «сикамов», благодаря их уникальным свойствам, могут найти эффективное широкое применение не только в Заполярье, но и в любых других регионах России, а также и в других странах. Освоение недр Заполярья и шельфовых зон морей Восточной Арктики на стартовой линейке. Япония в течение последних пяти лет вложила 58,8 млн $\$$ в создание промышленной технологии и уже проводит промышленные испытания по добыче природного газа из газогидратов [30].

\section{Экономические аспекты проекта}

В последней графе табл. 4 приведены цены материалов. Расчет стоимости $1 \mathrm{~m}^{3}$ петроситалла при массовом производстве взят, исходя из техникоэкономических параметров таких традиционных материалов и конструкций, как стеклокристаллические материалы, близкие по технологическим параметрам.

Структура себестоимости $1 \mathrm{~m}^{3}$ петроситалла при массовом производстве включает в себя: сырье и материалы - $40 \%$, зарплата - $30 \%$, энергия $14 \%$, амортизация - $8 \%$, прочие расходы - $8 \%$.

В случае размещения завода по производству петроситалла в п. Харп ЯНАО, стоимость природного газа - 3 тыс. p/тыс. м $^{3}$ или 50 долл. за тысячу $\mathrm{M}^{3}$ [31]. Расход газа на тепловые процессы около $400 \mathrm{~m}^{3}$ на производство одного кубометра петроситалла, или 1200 р. Исходя из удельных затрат на энергетику, примерная себестоимость $1 \mathrm{~m}^{3}$ петроситалла будет равна 8570 р., что ощутимо для любой экономики.

Применение петроситаллов будет означать переход на новый инновационный уровень нефтегазодобывающих предприятий. Намечается шесть факторов эффективности и интенсификации отрасли [9-11].

1) увеличение дохода от роста реализации продукции:

- ускорения темпов строительства;

- экономии газа, расходуемого на собственные нужды, и снижения его потерь;

2) снижение материальных и энергетических затрат:

- использования нового оборудования, новых технологий и технологических процессов;

- инноваций, направленных на снижение расхода материальных ресурсов;

- использования импортозамещающих материалов;

- замены используемых в производстве материалов, сырья или полуфабрикатов более дешевыми;

- оптимизации графиков проведения и методов производства капитального и текущего ремонта;
- уменьшения затрат на капитальный и текущий ремонт объектов инфраструктуры;

- повышения ремонтопригодности оборудования;

3) сокращение затрат живого труда при использовании нового оборудования, новых технологических процессов;

4) экономия времени:

- увеличения межремонтных периодов;

- повышения уровня интенсификации производства.

5) экономия капитальных вложений:

- совершенствования технических, технологических и организационных решений при строительстве зданий, сооружений и объектов;

- увеличения сроков полезного использования машин, оборудования, транспортных средств и других видов основных фондов;

- оптимизации корпоративных программ капитального строительства;

- использования прогрессивных технико-технологических и организационных решений;

- оптимизации газотранспортных и транспортных потоков;

6) факторы, связанные с повышением качества готовой продукции и изменением цен.

\section{Заключение}

1. Получены петроситаллы класса «сикам» из отвальных пород базитового и другого состава трех золоторудных месторождений Полярного Урала, достоверность которых подтверждена опытно-промышленными испытаниями.

2. Теоретически рассчитаны и экспериментально уточнены химические составы и технологические параметры процесса кристаллизации метасиликактных твердых растворов для получения качественных материалов СКС, необходимых для важнейших сегментов экономики Заполярья и Арктики взамен завозимых с «материка».

3. Петроситаллы по совокупности физико-химических свойств превосходят традиционные и аналогичные материалы, поэтому они могут быть использованы в качестве эффективного материала в технологических узлах со специфическими условиями работы. Высокая прочность и сопротивляемость истиранию, огне- и атмосферостойкость, химическая устойчивость делают этот материал долговечным.

4. По примеру развитых стран производство петроситаллов из промышленных отходов может частично решить проблему дефицита природных ресурсов.

5. Петроситаллы и конструкции в виде свай, плит, блоков, купольных сборных элементов в несколько раз дешевле, прочнее и долговечнее, чем конструкции из бетона и металла. Они очень скоро могут найти широкое применение в новой технике и многих отраслях экономики нашей страны и зарубежья. 


\section{СПИСОК ЛИТЕРАТУРЫ}

1. Саркисов П.Д., Орлова Л.А., Попович Н.В., Щеголева Н.Е., Лебедева Ю.Е., Гращенков Д.В. Современное состояние вопроса в области технологии и производства ситаллов на основе алюмосиликатных систем. Стеклообразование, кристаллизация и формообразование при получении стронций-анортитовых и цельзиановых ситаллов // Все материалы. - 2011. - № 8. - С. 1-19.

2. Мананков А.В. Физико-химические основы наноструктурной минералогии в получении современных материалов // Вестник ТГАСУ. - 2012. - № 2. - С. 120-136.

3. Павлушкин Н.М. Основы технологии ситаллов. - М.: Стройиздат, $1979 .-359$ c.

4. Стрнад 3. Стеклокристаллические материалы / пер. с чеш. И.Н. Князевой / под ред. Б.Г. Варшала. - М.: Стройиздат, 1988. -256 с

5. Мананков А.В., Страхов Б.С. Разработка новых композитных строительных конструкций на основе петроситаллов при создании промышленной и транспортной инфраструктуры добычи нефти и газа в Арктических районах // Вестник ТГАСУ. 2014. - № 2. - С. 167-176.

6. Мананков А.В., Владимиров В.М., Страхов Б.С. Высокопрочные петроситалловые конструкции для работы в особых условиях Арктики // Вестник ТГУ. - 2014. - № 386. - С. 223-233.

7. Мананков А.В., Горюхин Е.Я., Локтюшин А.А. Волластонитовые, пироксеновые и другие материалы из промышленных отходов и недефицитного природного сырья. - Томск: Изд-во ТГУ, 2002. -168 c.

8. Свидетельство № 92355 на товарный знак на новый 19 класскамни искусственные, строительные. Заявка № 118592. Приоритет товарного знака 07.02.1990 г.

9. Гасанова Э.Р., Мананков А.В. К решению проблем бездорожья при добыче полезных ископаемых в особых условиях // Материалы 63-й Университетской научно-технической конференции студентов и молодых ученых (УНТК-2017). - Томск: Изд-во ТГАСУ, 2017. - С. 64-66.

10. Мананков А.В., Гасанова Э.Р. Петроситаллы для транспортных инфраструктур Крайнего севера и Арктического шельфа // Вестник ТГАСУ, - 2017. - № 6. - С. 161-171.

11. Гасанова Э.Р., Мананков А.В. Петроситалловые строительные конструкции для обеспечения нефте-газодобычи в особых условиях Арктики // Материалы первого рязанского международного Экологического форума «Здоровая окружающая среда - основа безопасности регионов». - Рязань: РГУ имени С.А. Есенина, 2017. - С. 124-136.

12. Мананков А.В., Карауш С.А. Разработка высокорентабельной технологии производства пористых остеклованных блоков // Матер. сб. «Научно-инновационная деятельность Томского государ. архитект.-строит. ун-та в 2014 г.». - Томск: ТГАСУ, 2015. - C. $126-127$.

13. Materials for boiler pipes surface protection / M.Kh. Rumi, Sh.R. Nurmatov, E.P. Mansurova, M.A. Zufarov, Sh.A. Faiziev, G.V. Voronov, Sh.K. Irmatova // Glass and ceramic. - May 2017. - № 5. - P. 29-33.

14. Chemical resistance of materials based on fused mineral raw materials of Uzbekistan / M.Kh. Rumi, Sh.R. Nurmatov, E.P. Mansurova, M.A. Zufarov, Sh.A. Faiziev // Glass and ceramic. - July 2017. - № 7. - P. 32-36.

15. Минералого-геохимические и экспериментальные исследования синтеза петроситаллов / А.В. Мананков, Д.А. Бычков,
Б.С. Страхов, В.М. Яковлев, Н.Е. Быков // Минералогия, геохимия и полезные ископаемые Азии. - Томск: Изд-во Том. унта, 2012. - С. 10-18.

16. Мананков А.В., Владимиров В.М., Страхов Б.С. Механизм структурной организации и модель неравновесной кристаллизации стекол // Стекло и керамика. - 2015. - № 1. - С. 3-10.

17. Manankov A.V., Vladimirov V.M. On the mechanism and thermodynamic modeling of metasilicate glass ceramics crystallization // Glass and ceramic. - 2016. - № 6. - P. 3-7.

18. Mandelbrot B.B. The fractal geometry of nature. - New York: W.H. Freeman and Company, 1982. $-464 \mathrm{p}$.

19. Schindler M., Berti D., Hochella M.F. Previously unknown mineralnanomineral relationships with important environmental consequences: the case of chromium release from dissolving silicate minerals // American Mineralogist. - 2017. - № 102 (10). - P. 2142-2145.

20. Crystallization and second harmonic generation of lithium niobium silicate glass ceramics / H. Vigouroux, E. Fargin, A. Fargues, B.L. Garrec, M. Dussauze, V. Rodriguez, F. Adamietz, G. Mountrichas, E. Kamitsos, S. Lotarev, V. Sigaev // Journal of the American Ceramic Society. - 2011. - V. 94. - № 7. - P. 2080-2086.

21. Medvedev E.F., Min'ko N.I. Silicate glasses permeability to hydrogen // Glass and ceramic. -2017 . - № 1. - P. 3-6.

22. Stookey J.D. Catalyzed crystallization of glass in theory and practices // Glasstechn. Berichte. - 1959. - № 5. - P. 32

23. Crystallization of $\left(\mathrm{Na}_{2} \mathrm{O}-\mathrm{MgO}\right)-\mathrm{CaO}-\mathrm{Al}_{2} \mathrm{O}_{3}-\mathrm{SiO}_{2}$ Glassy Systems Formulated from Waste Products / L. Barbieri, A.M. Ferrari, I. Lancellotti, C. Leonelli // Journal of the American Ceramic Society. - 2000. - V. 83. - Iss. 10. - P. 2515-2520.

24. Systematic approach to secondary products implementation in glass-making / N.I. Min'ko, 0.A. Dobrinskaya, K.N. Gridyakin, A.S. Bulgakov // Glass and ceramic. - 2017. - № 5. - P. 3-6.

25. Романов Б.М., Мананков А.В., Сазонов А.М. 0 фазовых и структурных соотношениях в системе энстатит-диопсид при атмосферном давлении // Геология и геофизика. - 1981. № 10. - С. $67-76$.

26. Мананков А.В., Локтюшин А.А. Твердофазное состояние в голографической модели вещества // Актуальные вопросы современной науки: Материалы Международной научно-практической конф. Ч. 1 (4), - Томск: Изд-во Дендра, 2018. C. $22-52$.

27. Мананков А.В., Гасанова Э.Р., Быкова В.В. Физико-химические и технологические аспекты разработки ситаллов нового класса // Вестник ВГУИТ. - 2018. - Т. 80. - № 1. - С. 211-222.

28. Способ определения параметров кристаллизации силикатных стекол : пат. РФ. № 4797249/33; опубл. 15.01.93. Бюл. № 2.

29. СТ0 Газпром РД 1.12-096-2004. Внутрикорпоративные правила оценки перспективности НИОКР. 01.10.2008.

30. Мананков А.В., Бычков Д.А., Страхов Б.С. Технико-экономическое обоснование применения новых строительных конструкций и технологий на основе петроситаллов // Россия в Арктике XXI век: среда обитания, общество, освоение. Томск: ТПУ, 2012. - С. 200-203.

31. Manankov A.V., Gasanova E.R., Xaritonova N.V. Crystal-Chemical Principles Underlying Monomineralic Composition Calculation for Glass-Ceramics // Inorganic Materials. - 2018. - V. 54. № 9. - P. 40-48.

Поступила 07.07.2018 г.

\section{Информация об авторах}

Мананков А.В., доктор геолого-минералогических наук, профессор, профессор Томского государственного архитектурно-строительного университета; профессор Национального исследовательского Томского государственного университета.

Гасанова Э.Р.к., аспирант Томского государственного архитектурно-строительного университета. 
UDC 54-165.2+624.139

\title{
SITALS MADE FROM LOCAL RAW MATERIALS FOR INDUSTRIAL INNOVATION INFRASTRUCTURES WITH HIGH TECHNO-ECONOMIC EFFICIENCY IN EXTREME CONDITIONS OF THE FAR NORTH
}

\author{
Anatoliy V. Manankov ${ }^{12}$, \\ mav.39@mail.ru \\ Elgyul R. Gasanova', \\ elgyul91@mail.ru \\ 1 Tomsk State University of Architecture and Building, \\ 2, Solyanaya Square, Tomsk, 634003, Russia. \\ ${ }^{2}$ National Research Tomsk State University, \\ 36, Lenin avenue, Tomsk, 634050, Russia.
}

The relevance of the research is determined by the problems of the effective mineral exploration in the Arctic due to refusal to use building materials (concrete products, bricks, etc.) imported from thousands of kilometers away. The maximum distance from industrial-urban centers combined with the extremely severe natural and climatic conditions of the Far North significantly affect the economy of extraction and the ecology of the territory, where the cost of building materials reaches $70 \%$ of the oil and gas cost. The access to the shelves of the Arctic seas of Russia and other countries requires innovative materials and breakthrough technologies, including the construction of artificial islands and underwater structures on the shelf. The implementation of these innovative technologies requires materials and structures with higher strength and durability.

The main aim of the research was to develop multifunctional rock-glass ceramics based on the Polar Urals raw materials with a unique combination of physical, mechanical and chemical properties for advanced technologies.

Objects of researches: dump rocks of the basic rock class of the Polar Urals gold fields, metasilicate melts, glass and sitall (glass-ceramics).

Methods of researches: theoretical and experimental studying of raw materials; calculation of the feed composition for metasilicate glass-ceramics - a new class «sikam» (SCS); methods for determining the main technological parameters, studying the basic properties of products, methods for creating new innovative building structures; methods for substantiating technical and economic indicators. The chemical composition of the feedstock is determined by mass spectroscopic methods with inductively coupled plasma.

Research results. The research has substantiated the original compositions and established the physico-chemical properties of rock glassceramics from the local raw materials of the Polar Urals gold fields. The research introduces the economic efficiency and environmental usefulness of this material production on site with the use of a cheap energy carrier (associated gas) in comparison with imported reinforced concrete. In special Arctic conditions, this material is indispensable for production of a pile-trestle road structure and construction of a durable transport infrastructure on its basis, industrial and civil facilities in the conditions of permafrost and the Arctic shelf.

Key words:

Rocks of the Polar Urals, rock glass-ceramics, isomorphism, monominerality, metasilicates, subsolidus immiscibility, spinodal decomposition, sikam, crystallochemical approach, pile-trestle road structure, transport, commercial, civil infrastructure.

\section{REFERENCES}

1. Sarkisov P.D., Orlova L.A., Popovich N.V. Current state of the matter in the field of technology and production of glass-based aluminosilicate systems. Glass Formation, Crystallization and Formation in Preparation of Strontium-Anorthite and Celcine Sital Stalks. All Materials, 2011, no. 8, pp. 1-19. In Rus.

2. Manankov A.V. Physicochemical foundations of nanostructured mineralogy in obtaining modern materials. Bulletin of Tomsk state architecture-building university, 2012, no. 2 (35), pp. 120-136. In Rus.

3. Pavlushkin N.M. Osnovy tehnologii sitallov [The fundamentals of sital technology]. Moscow, Stroyizdat Publ., 1979. 340 p.

4. Strnad Z. Steklokristallicheskie materialy [Glass-crystal materials]. Translated from Czech by I.N. Knyazeva. Ed. by B.G. Varshal. Moscow, Stroyizdat Publ., 1988. 256 p.

5. Manankov A.V., Strakhov B.S. Development of new composite building structures based on rock glass-ceramics in creating industrial and transport infrastructure of oil and gas in the Arctic. Vestnik TGASU, 2014, no. 2, pp. 167-176. In Rus.

6. Manankov A.V., Vladimirov V.M., Strakhov B.S. Rock glass-ceramics high strength design for working in special conditions in the Arctic. Bulletin of TSU, 2014, no. 386, pp. 223-233. In Rus.

7. Manankov A.V., Goryukhin E.Ya., Loktyushin A.A. Vollastonitovye, piroksenovye i drugie materialy iz promyshlennykh otkhodov $i$ nedefitsitnogo prirodnogo syrya [Wollastonite, pyroxene and other materials from industrial waste and non-deficient natural raw materials]. Tomsk, Tomsk State University Press, 2002. $168 \mathrm{p}$.

8. Tovarny znak na novy 19 klass - kamni iskusstvennye, stroitelnye. Svidetelstvo № 92355 [Certificate No. 92355 for trademark for new 19 class - artificial stones, construction]. Zayavka № 118592 [Application No. 118592]. Priority of the trademark on 07.02.1990.

9. Gasanova E.R., Manankov A.V. K resheniyu problem bezdorozhya pri dobyche poleznykh iskopayemykh v osobykh usloviyakh [On solution of off-road problems in extraction of minerals in special conditions]. Materialy 63-y universitetskoy nauchnotekhnicheskoy konferentsii studentov i molodykh uchenykh [Proc. of the $63^{\text {rd }}$ University scientific and technical conference of students and young scientists (UNTC-2017)]. Tomsk, 2017. pp. 64-66.

10. Manankov A.V., Gasanova E.R. Rock glass-ceramics for transport infrastructures of the Far North and the Arctic shelf. Vestnik TGASU, 2017, no. 6, pp. 161-171. In Rus.

11. Gasanova E.R., Manakov A.V. Petrositallovye stroitelnye konstruktsii dlya obespecheniya nefte-gazodobychi v osobykh usloviyakh Arktiki [Rock glass-ceramics building construction for oil and gas production in special conditions of the Arctic]. Zdorova- 
ya okruzhayushchaya sreda - osnova bezopasnosti regionov. $\mathrm{Ma}$ terialy pervogo ryazanskogo mezhdunarodnogo ekologicheskogo foruma [Healthy environment is the basis of regional security. Materials of the first Ryazan international Environmental forum]. Ryazan, RSU named after S.A. Esenin, 2017. pp. 124-136. In Rus.

12. Manankov B.A., Karaush S.A. Razrabotka vysokorentabelnoy tekhnologii proizvodstva poristykh osteklovannykh blokov [Development of highly profitable technique for producing porous vitrified blocks]. Materialy sbornika. Nauchno-innovatsionnaya deyatelnost Tomskogo gosudarstvennogo arkhitekturno-stroitelnogo universiteta $v 2014 \mathrm{~g}$. [Materials of reference book. Scientific and innovative activity of the Tomsk state architecture-building university in 2014]. Tomsk, TGASU Press, 2015. pp. 126-127.

13. Rumi M.Kh., Nurmatov Sh.R., Mansurova E.P., Zufarov M.A., Faiziev Sh.A., Voronov G.V., Irmatova Sh.K. Materials for boiler pipes surface protection. Glass and ceramic, 2017, no. 5, pp. 29-33.

14. Rumi M.Kh., Nurmatov Sh.R., Mansurova E.P., Zufarov M.A., Faiziev Sh.A. Chemical resistance. of materials based on fused mineral raw materials of Uzbekistan. Glass and ceramic, 2017, no. 7, pp. 32-36.

15. Manankov A.V., Bychkov D.A., Strakhov B.S., Yakovlev V.M., Bykov N.E. Mineralogo-geokhimicheskie i eksperimentalnye issledovaniya sinteza petrositallov [Mineralogical-geochemical and experimental study of synthesis of rock glass-ceramics]. Mineralogiya, geokhimiya i poleznye iskopaemye Azii [Mineralogy, Geochemistry and minerals of Asia]. Tomsk, Tomsk State University Press, 2012. pp. 10-18.

16. Manankov A.V., Vladimirov V.M., Strakhov B.S. Mechanism of structural organization and model of nonequilibrium crystallization of glasses. Glass and ceramics, 2015, no. 1, pp. 3-10.

17. Manankov A.V., Vladimirov V.M. Mechanism and construction of a thermodynamic model for crystallization of sitalites of a metasilicate composition. Glass and ceramics, 2016, no. 6, pp. 3-8.

18. Mandelbrot B.B. The fractal geometry of nature. New York, W.H. Freeman and Company, 1982. $464 \mathrm{p}$.

19. Schindler M., Berti D., Hochella M.F. Previously unknown mineral-nanomineral relationships with important environmental consequences: The case of chromium release from dissolving silicate minerals. American Mineralogist, 2017, no. 102 (10), pp. 2142-2145.

20. Vigouroux H., Fargin E., Fargues A., Garrec B.L., Dussauze M., Rodriguez V., Adamietz F., Mountrichas G., Kamitsos E., Lotarev S., Sigaev V. Crystallization and second harmonic generation of lithium niobium silicate glass ceramics. Journal of the American Ceramic Society, 2011, vol. 94, no. 7, pp. 2080-2086.
21. Medvedev E.F., Min'ko N.I. Silicate glasses permeability to hydrogen. Glass and ceramic, 2017, no. 1, pp. 3-6.

22. Stookey J.D. Catalyzed crystallization of glass in theory and practices. Glasstechn. Berichte, 1959 , no. 5, p. 32.

23. Barbieri L., Ferrari A.M., Lancellotti I., Leonelli C. Crystallization of $\left(\mathrm{Na}_{2} \mathrm{O}-\mathrm{MgO}\right)-\mathrm{CaO}-\mathrm{Al}_{2} \mathrm{O}_{3}-\mathrm{SiO}_{2}$ Glassy Systems Formulated from Waste Products. Journal of the American Ceramic Society, 2000, vol. 83, Iss. 10, pp. 2515-2520.

24. Min'ko N.I., Dobrinskaya 0.A., Gridyakin K.N., Bulgakov A.S. Systematic approach to secondary products implementation in glass-making. Glass and ceramic, 2017, no. 5, pp. 3-6.

25. Romanov B.M., Manakov A.V., Sazonov A.M. About phase and structural relationships in the enstatite-diopside system at atmospheric pressure. Russian Geology and Geophysics, 1981, no. 10, pp. 67-76. In Rus.

26. Manankov A.V., Laktyushin A.A. Tverdofaznoe sostoyanie v golograficheskoy modeli veshchestva [Solid state in a holographic model of a substance]. Aktualnue voprosy sovremennoy nauki. Materialy Mezhdunarodnoy nauchno-prakticheskoy konferentsii [Topical issues of modern science. Materials of International scientific-practical conference]. Tomsk, Dendra Publ., 2018. P. 1 (4), pp. 22-52.

27. Manankov A.V., Gasanova E.R., Bikova V.V. Physico-chemical and technological aspects of development of new class sitalls. Proceeding of VSUET, 2018, vol. 80, no. 1, pp. 211-222. In Rus.

28. Manakov A.V., Laktyushin A.A. Sposob opredeleniya parametrov kristallizatsii silikatnykh stekol [Method of definition of silicate glasses crystallization parameters]. Patent RF no. 4797249/33, 1993.

29. STO Gazprom RD 1.12-096-2004. Vnutrikorporationye pravila otsenki perspektivnosti NIOKR [Internal rules for assessing the prospects of R\&D]. 01.10.2008.

30. Manankov A.V., Bychkov D.A., Strakhov B.S. Tekhniko-ekonomicheskoe obosnovanie primeneniya novykh stroitelnykh konstruktsiy i tekhnologiy na osnove petrositallov [Feasibility study of application of new building structures and technologies on the basis of rock glass-ceramics]. Rossiya $v$ Arktike XXI vek: sreda obitaniya, obshchestvo, osvoenie [Russia in the Arctic of the XXI century: environment, society, development]. Tomsk, TPU Publ. house, 2012. pp. 200-203.

31. Manankov A.V., Gasanova E.R., Kharitonova N.V. Crystal-Chemical Principles Underlying Monomineralic Composition Calculation for Glass-Ceramics. Inorganic Materials, 2018, vol. 54, no. 9 , pp. $40-48$.

Received: 7 July 2018.

\section{Information about the authors}

Anatoliy V. Manankov, Dr. Sc., professor, Tomsk State University of Architecture and Building; professor National Research Tomsk State University.

Elgyul R. Gasanova, post-graduate student, Tomsk State University of Architecture and Building. 